\title{
Effect of Illustrated Home-Based Exercise Regime over Verbal Exercise Prescription on Adherence Levels to Home exercises and Functional ability among Stroke Survivors -A Pilot Study
}

\author{
Neha Rastogi ${ }^{1 *}$, Ajeet Kumar Saharan², Ramakant Yadav ${ }^{3}$, Manisha Saharan, \\ Gowrishankar Potturi ${ }^{5}$, Maliram Sharma ${ }^{6}$ and Dharamchand Jain ${ }^{7}$ \\ ${ }^{\prime *}$ PhD Scholar, Jaipur Physiotherapy College, M.V.G University, Jaipur, India \\ ${ }^{2}$ Department of Physiotherapy, Jaipur Physiotherapy College, M.V.G University, Jaipur, India \\ ${ }^{3}$ Department of Neurology, Uttar Pradesh University of Medical Sciences, Saifai, Etawah, India \\ ${ }^{4,6}$ PhD Scholar, Jaipur Physiotherapy College, M.V.G University, Jaipur, India \\ ${ }^{5}$ Department of Physiotherapy, Uttar Pradesh University of Medical Sciences, Saifai, Etawah, India \\ ${ }^{7}$ Department of Orthopedics, Jaipur Physiotherapy College, M.V.G University, Jaipur, India \\ Corresponding author email: physioneha05@gmail.com
}

\section{ABSTRACT}

Stroke is a rapidly increasing clinical manifestation of a focal impairment of cerebral function that lasts longer than 24 hours with no apparent cause other than the vascular origin. Due to the advancement in science and art of medical technology, hospitalization of the patient has reduced from weeks to days. Though patient is discharged, home rehabilitation is vital for attaining complete functional abilities. This study focuses on efficacy of Home-Based Exercise Regime over Verbal Exercise Prescription on Adherence Levels to Home exercises and Functional ability among Stroke Survivors. Patients admitted directly or discharged from the hospital within the last 1-6 months and who meet the inclusion criteria were included in the study after written informed consent. Patients were divided into Group A (Control) who received a home-based exercise program with verbal instructions for 1 hour/day, and Group B (Experimental) receives a bilingualpictorial exercise program brochure to be completed at home for 1 hour/day. Both groups receive a patient self-report scale, which must be completed and carefully filled out at home, under the direct supervision of the caretaker. The Barthel Index scale was used to determine functional abilities of daily living. The mean differences between pretest and post-test Barthel Index in Group A is 3.3, and that of group B is 5.5. With't' value=3.11, the test is significant at $\mathrm{p}<0.05$, indicating group $\mathrm{B}$ have improved scores than group A which are statistically significant. The mean of the patient self-report scale of Group A is 100.80, and that of Group B are 121.15, with ' $t$ 'value $=2.81$. The test is significant at $\mathrm{p}<0.05$. Group B showed a significant increase in exercise adherence levels than group A. The results of this study indicate that an illustrated home exercise programme motivates and increases adherence to home exercises, thereby improvingfunctional abilities in stroke survivors more than verbal exercise prescriptions.

\section{KEY WORDS: PHYSIOTHERAPY, REHABILITATION, HOME-BASED EXERCISE PROGRAMME, STROKE.}

Biosc Biotech Res Comm P-ISSN: 0974-6455 E-ISSN: 2321-4007

\section{crossef}

Identifiers and Pagination

Year: 2021 Vol: 14 No (7) Special Issue Pages: 191-195

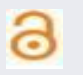
c) creative commons Article Information Received: $15^{\text {th }}$ May 2021 Accepted after revision: $18^{\text {th }}$ July 2021

This is an open access article under Creative

Commons License Attribn 4.0 Intl (CC-BY).

DOI: http://dx.doi.org/10.21786/bbrc/14.7.45

\section{INTRODUCTION}

According to WHO, Stroke is defined as rapidly rising clinical signs of focal (or global) disturbance of cerebral function which persist beyond 24 hours with no apparent cause other than vascular origin. (Truelsen 2006) Stroke represents the sudden death of some brain cells because of lack of oxygen or due to arterial blockage or rupture and is, in addition, a leading cause of dementia and 
depression (Owolab ,et al 2015).Stroke is a global health issue, the second leading cause of death and the third leading cause of disability worldwide (World Health Organization, 2016). 70\% of strokes and $87 \%$ of both stroke and disability-related deaths occur in low- and middle-income countries (Feigin et al 2014).

It is a devastating, expensive medical condition affecting not only the disabled, but also the connected relatives and care givers. It is detected that approximately 20 million people each year suffer from stroke, and 5 million will not survive. The I.C.M.R. (2004) report reveals that stroke contributes to $41 \%$ of deaths and $72 \%$ of disability amongst the non-communicable diseases in India. The Indian National Commission on Macro-economic and health estimated that the number of strokes increased from 1,081,480 in 2000 to 1,667,372 in 2015 (Shah and Mathur 2010). Worldwide over the past four decades, the annual age-standardized stroke incidence rate has typically decreased by $1.1 \%$ in high-income countries but has increased by $5.3 \%$ in low to middle-income countries (Pandian et al 2021).

Post-stroke survival rates have increased, causing many individuals who had a stroke with extended-term physical and psychological impairments as well as functional limitations (Johanne Desrosiers and Daniel Bourbonnais 2005 and Miller 2008). The individual's recovery is seldom complete at the time of discharge from rehabilitation (Duncan et al 2003). Many of the patients $\mathrm{n}$ caregivers do not have enough resourcesfor engaging in exercise activities after discharge from rehabilitation services (Macko et al 2005). Some patients experience declining mobility skills after discharge from rehabilitation. Post-stroke rehabilitation training traditionally focuses on basic mobility and activities of daily living (A.D.L.) (Shaughnessy et al 2014).

Proper care for stroke survivors is essential as it may cause many neurological deficits that can lead to functional impairments. The patient's post-dischargeable home exercises program and family support are too overwhelmed to continue with the prescribed exercises (Schneiders et al 1998). Published research conducted on low back pain for Adherence with various prescriptions of exercises set-up that the patients received verbal instruction plus a brochure (written and pictorial instructions) had a higher adherence rate of $77.4 \%$ versus 38. $1 \%$ for patients receiving verbal instruction only (Duncan et al 2002).

The home-based exercise program provides a positive effect on the functional outcome in post-stroke survivor (Schoo et al 2005). Physical therapists may have the opportunity to influence the patient's long-term management of their disability via home based-based communication through prescription, education, and follow-ups. Therefore, this study is undertaken to assess the effect of illustrated home-based exercise regime over verbal exercise prescription on adherence levels to home exercises and functional abilities among stroke survivors.

\section{MATERIAL AND METHODS}

Enrollment and Ethical approval: The study was conducted at Department of Neurology and Rehabilitation of the university hospital. The study got its ethical clearance from the institutional ethical committee with the ethical number 95/2018.

Subject Recruitment: After satisfying the inclusion criteria and informed consent, 40 patients going discharge from the hospital wererandomly divided into Group A (control) and Group B(experimental) by even and odd numbering. Post-stroke patients discharged from the hospital in previous 1-6 months, post-stroke patients who can do home exercises,30-60 years of age in the last 1-6 months, Patients who have a caregiver present for a physiotherapy session, consent to actively participate, who can read and understand were included in the study. Participants were excluded if they had Bedsores, Cardio-respiratory complications, patients with other physical impairments before the stroke.

Study design: Single blinded randomized pilot study, where patients are blinded.

Procedure: Both groups are first assessed for neurological dysfunction followed by the functional independence. The functional independence evaluation is carried out by a Barthel index scale serving the baseline of the patient's functions. The intervention is started using conventional exercises for both the groups till discharge dates. (Table-1)

Table 1. Conventional Exercise protocol in the hospital

\begin{tabular}{l|c|}
\hline Exercises & Duration \\
\hline Passive Stretching (U/L and L/L) & $15 \mathrm{~min}$ \\
\hline PNF (U/L and L/L) & $15 \mathrm{~min}$ \\
\hline Reach outs & $5 \mathrm{~min}$ \\
\hline Weight bearing exercises & $5 \mathrm{~min}$ \\
\hline Supine bridging (bilateral) & $5 \mathrm{~min}$ \\
\hline Ankle toe movements & $5 \mathrm{~min}$ \\
\hline $\begin{array}{l}\text { Walking (around the bed or } \\
\text { corridor) accordingly }\end{array}$ & $10 \mathrm{~min}$ \\
*U/L indicates= upper limb; L/L = lower Limb \\
\hline
\end{tabular}

At the time of discharge from the hospital, the subject and caregivers of Group-A wereverbally instructed for the conventional based home exercises program (H.E.P) for 1hour/day. The caregivers of group-B were instructed for the H.E.P for 1 hour/day with the prescribed homebased exercise program brochure to be taken at home in $\{$ written $n$ pictorial $\}$ format (bilingually).(Table-2) The patient exercises are selected from a compilation of exercises to maintain some level of control. The compilation was based on the standard set of exercises 
prescribed for stroke rehabilitation concerning the current literature.

The home-based exercises were carefully documented on the prescription sheet attached to each patient's demographic and assessment sheet. The self report scale(SRS) covered 30 days with the specific dates and days for daily recording of the prescribed exercises by the caregiver. Thedata in the form of patient self-report scale for measuringAdherence to home-based exercise is given to both the group caregivers who will note, evaluate, and countersign the self-report scale for authentication and for the participation of the patient to the home-based exercise program and they should also mention the reasons for non-adherence. There were moreover specific columns for the time that the exercises were started and ended to record the timeit took to complete the home exercise program by the patient. The participants were followed-up after 30 days by sending text on e-media or by reminding telephonically. This is followed by assessing whether the self-report scale is completed and administered. The Barthel Index score was recorded at follow-up.

\begin{tabular}{|c|c|c|}
\hline Groups & $\begin{array}{c}\text { Group A } \\
\text { Same exercises } \\
\text { instructed verbally } \\
\text { at the time of discharge }\end{array}$ & $\begin{array}{c}\text { Group B } \\
\text { Same exercises given in } \\
\text { a brochure in written } \\
\text { and pictorial format }\end{array}$ \\
\hline $\begin{array}{l}\text { Exercises } \\
\text { ( } 15 \text { exercises) }\end{array}$ & \multicolumn{2}{|c|}{$\begin{array}{l}\text { Towel slide, Shoulder shrug, External rotation with cane, } \\
\text { Reach out, Weight bearing exercises U/L, Hip abduction in } \\
\text { standing, Weight bearing exercises in L/L(Hip flexion), } \\
\text { Weight bearing exercises in L/L (knee flexion),Lying } \\
\text { terminal extension, Supine bridging, Heellifts, Toe lifts, } \\
\text { Sitting knee extension, Hip extension, and Toe standing }\end{array}$} \\
\hline No of repetitions & \multicolumn{2}{|l|}{4 times per exercise } \\
\hline Duration & \multicolumn{2}{|l|}{1 hour per day } \\
\hline
\end{tabular}

\begin{tabular}{|c|c|c|c|c|c|c|}
\hline S.No & Characteristic & $\begin{array}{l}\text { Group A }(\mathrm{n}=20) \\
{[\mathrm{U} \text { score }]}\end{array}$ & $\begin{array}{c}\text { Group B }(\mathrm{n}=20) \\
\quad[\mathrm{U} \text { score }]\end{array}$ & Z score & P value & $\begin{array}{c}\text { Significance } \\
\text { (Data with Normal } \\
\text { Distribution) }\end{array}$ \\
\hline 1 & Age (Years) ${ }^{*}$ & $52(\mathrm{IQR}=8)[244]$ & $55(\mathrm{IQR}=11)[156]$ & -1.18 & 0.20 & \multirow{6}{*}{$\mathrm{p}>0.05$} \\
\hline 2 & Gender (Male: female) & $12(60): 8(40)[210]$ & 11(55):9(45) [190] & -0.30 & 0.76 & \\
\hline 3 & Etiology (Ishemic:Hemorrhagic) & $13(65): 7(35)[150]$ & 18(90):2(10) [250] & 1.85 & 0.06 & \\
\hline 4 & Side of hemiplegia (Right: left) & $15(75): 5(25)[200]$ & $15(75): 5(25)[200]$ & -0.01 & 0.98 & \\
\hline 5 & $\begin{array}{l}\text { Time post stroke before Recruitment } \\
\text { (in days) }\end{array}$ & 12 [178.5] & $8.5[221.5]$ & 0.57 & 0.56 & \\
\hline 6 & Literate:Illeterate & 16(80):4(20) [200] & $16(80): 4(20)[200]$ & -0.01 & 0.98 & \\
\hline
\end{tabular}

Outcome Measures: The Barthel Index assesses the functional abilities of daily living at the time of enrollment (t0) and after 30 days at follow up (t1). The Adherence to the home exercise program was evaluated by patient self-report scale (SRS), submitted at followup.

Statistical Analysis: This study analyzes the profound effect of illustrated home-based exercise regime over verbal exercise prescription on adherence levels to home exercises and functional abilities among stroke survivors.
The baseline demographic data and group characteristics were analyzed for normal distribution of data by using Mann Whitney U test. (Table-3) All pre-test and post-test scores of Barthel index and patient self-report scale were expressed as a mean. They were statistically analyzed using paired t-test within the groups and unpaired ttest between the groups to accurately determine the statistical difference among the group at $95 \%$ confidence level $(\mathrm{P}<0.05)$. 


\section{RESULTS AND DISCUSSION}

To analyze the effect of illustrated home-based exercise regime over verbal exercise prescription on adherence levels to home exercises and functional abilities among stroke survivors, the baseline characteristics of Group A and Group comes from the normal distribution and have no statistical significant difference. (Table-3) The pre test (t0) Barthel Index mean of Group A is 6.30, and the post-test $(\mathrm{t} 1)$ medianis 9.60 The $(\mathrm{t} 0)$ mean of Barthel Index of Group B is
7.95 and the (t1) mean 13.45. The $\mathrm{m}$ e a $\mathrm{n}$ differences between $(\mathrm{t} 0)$ and $(\mathrm{t} 1)$ of Barthel Index in Group A is 3.3, and that of group B is 5.5. With' $t$ ' value $=3.11$, the test is significant at $\mathrm{p}<0.05$, indicating that group $\mathrm{B}$ have improved scores than group A which are statistically significant. The mean of the patient self-report scale of GroupA is 100.80 and that of Group B are 121.15, with " $\mathrm{t}$ " value $=2.81$, the test is significant at $\mathrm{p}<0.05$. Group B showed a significant increase in exercise adherence levels than group A (Table 4).

\begin{tabular}{|c|c|c|c|c|c|c|c|c|}
\hline Group & $\begin{array}{l}\text { Barthel index } \\
\left(\mathrm{t}_{0}\right)^{*}\end{array}$ & $\begin{array}{l}\text { Barthel index } \\
\left(\mathrm{t}_{1}\right)^{*}\end{array}$ & tvalue & $\begin{array}{c}\text { Barthel index } \\
\left(\mathrm{t}_{1-1} \mathrm{t}_{\mathrm{t}}\right)^{*} \\
\text { difference }\end{array}$ & t value & $\begin{array}{l}\text { Self report } \\
\text { scale(SRS) }\end{array}$ & t value & $p$ value \\
\hline Group A & $6.30 \pm 2.96$ & $9.60 \pm 3.07$ & 11.33 & $3.3 \pm 1.30$ & \multirow{2}{*}{3.11} & $100.80 \pm 27.53$ & \multirow{2}{*}{2.81} & \multirow{2}{*}{$\mathrm{P}<0.05$} \\
\hline Group B & $7.95 \pm 3.71$ & $13.45 \pm 4.47$ & 8.55 & $5.5 \pm 2.87$ & & $121.15 \pm 16.98$ & & \\
\hline
\end{tabular}

The purpose of this study is to compare the effect of an illustrated home-based exercise regime versus a verbal exercise prescription on adherence to home exercises and functional abilities in stroke survivors. It is found that illustrated home-based exercise regime was effective over verbal instruction in exercise prescriptions on adherence levels to exercise at home and improve functional abilities. The Barthel Index (B.I.) is a valid, reliable, and appropriate scale to assess the patient's functional capabilities of independence in completing activities of daily livings. It has a total score of 20 , the higher the score, the more independent the patient.

In our study, both Group-A (control) and Group-B (experimental) had pre-test scores indicating their functionally disabled status. After the intervention the scores improved in both groups with the significant improvement seen in Group-B (experimental). Changes in more than 2 points in the total scores reflect a possible genuine change evident in our study.

Group-B (experimental) was given an illustrated home exercise program with a clear demonstration of exercises to be done at home. There was an improvement in Barthel index scores in Group-B than in Group-A, indicating that the patient of Group-B was regular at their exercise regimes due to motivation and showing interest by the illustrated images of exercises whereas, in Group-A (control), it was a simple single verbal instruction. The patient self-report scale is a self-evaluated scale used for the measurement of adherence to home-based exercises. It quantitatively measures the adherence to exercises by rubrics per number of exercises. It has a total score of 5 for 15 exercises to be completed per day. The study assessed the patient for 30 days, thus making a total score of 150. Group-B showed high Scores than Group-A, indicating that the illustrated home-based exercises will make the patient more adherent to exercise programs at home than verbal illustrated exercises.
There was limited research in this field of study about the techniques to improve the adherence level of patients to exercises. Schoo et al. (2005) conducted research and looked at various modes of prescription and adherence to the exercise program. The participants were randomized into three groups. All groups received face-to-face verbal instruction. The three methods of prescription investigated were a brochure, a brochure with a videotape, and a brochure with an audiotape. The study concluded that the addition of a videotape or an audiotape did not increase adherence rates to a home exercise program. Coombs et al. (2007) stated that stroke survivors must face the pervasive effect in their lives after discharge from the hospital. Hence, it becomes essential for the family members to learn rehabilitation techniques and adjust to their relationships with stroke survivors. Sheetal Kara (2015) investigated a need to focus on interventions that can improve adherence to home exercise programs, e.g., implementing a monitoring system such as an exercise logbook.

\section{CONCLUSION}

From this study, it is concluded that an illustrated homebased exercises regime has better adherence to participation in the prescribed exercises, with increased functional independence and vigourity than verbal communications among stroke survivors. It is recommended that the physiotherapists and other rehabilitation professionals can incorporate illustrated home-based exercise regimes in their home rehabilitation protocols.

\section{ACKNOWLEDGMENTS}

We would like to express our gratitude to the authorities of Uttar Pradesh University of Medical Sciences, Saifai, Etawah, for permitting to conduct this study in the department of Neurology and Rehabilitation. The authors would also like 
to thank department of physiotherapy for providing all possible support. We thank all the patients who actively participated in this study. We also extend our gratitude to the hospital staff members for their guidance and timely help throughout the study.

Funding: The study was not funded by any organization.

\section{Conflict of Interest: Nil.}

\section{REFERENCES}

Coombs, U.E., 2007. Spousal caregiving for stroke survivors. Journal of Neuroscience Nursing, 39(2), pp.112-119.

Duncan, P., Studenski, S., Richards, L., Gollub, S., Lai, S.M., Reker, D., Perera, S., Yates, J., Koch, V., Rigler, S. and Johnson, D., 2003. Randomized clinical trial of therapeutic exercise in subacute stroke. Stroke, 34(9), pp.2173-2180.

Duncan, P.W., Horner, R.D., Reker, D.M., Samsa, G.P., Hoenig, H., Hamilton, B., LaClair, B.J. and Dudley, T.K., 2002. Adherence to postacute rehabilitation guidelines is associated with functional recovery in stroke. Stroke, 33(1), pp.167-178.

Feigin, V.L., Forouzanfar, M.H., Krishnamurthi, R., Mensah, G.A., Connor, M., Bennett, D.A., Moran, A.E., Sacco, R.L., Anderson, L., Truelsen, T. and O'Donnell, M., 2014. Global and regional burden of stroke during 1990-2010: findings from the Global Burden of Disease Study 2010. The lancet, 383(9913), pp.245-255.

Haacke, C., Althaus, A., Spottke, A., Siebert, U., Back, T. and Dodel, R., 2006. Long-term outcome after stroke: evaluating health-related quality of life using utility measurements. Stroke, 37(1), pp.193-198.

Johanne Desrosiers, O.T. and Daniel Bourbonnais, O.T., 2005. Participation after stroke compared to normal aging. J Rehabil Med, 37, pp.353-357.

Kara, S. and Ntsiea, M.V., 2015. The effect of a written and pictorial home exercise prescription on adherence for people with stroke. Hong Kong Journal of Occupational Therapy, 26, pp.33-41.
Macko, R.F., Ivey, F.M., Forrester, L.W., Hanley, D., Sorkin, J.D., Katzel, L.I., Silver, K.H. and Goldberg, A.P., 2005. Treadmill exercise rehabilitation improves ambulatory function and cardiovascular fitness in patients with chronic stroke: a randomized, controlled trial. Stroke, 36(10), pp.2206-2211.Owolabi, M.O., Arulogun, O., Melikam, S., Adeoye, A.M., AkaroloAnthony, S., Akinyemi, R., Arnett, D., Tiwari, H., Miller, K.K., 2008. Adherence with home exercise programs 16 months after discharge from physical therapy by individuals post-stroke (Doctoral dissertation).

Gebregziabher, M., Jenkins, C. and Lackland, D., 2015.

The burden of stroke in Africa: a glance at the present and a glimpse into the future. Cardiovascular journal of Africa, 26(2 H3Africa Suppl), p.S27.

Pandian, J.D., Verma, S.J., Arora, D., Sharma, M., Dhaliwal, R., Khatter, H., Huilgol, R., Sylaja, P.N., Dhasan, A., Renjith, V. and Pathak, A., 2021. INSTRuCT: Protocol, Infrastructure, and Governance. Stroke, pp.STROKEAHA-120.

Schneiders, A.G., Zusman, M. and Singer, K.P., 1998. Exercise therapy compliance in acute low back pain patients. Manual therapy, 3(3), pp.147-152.

Schoo, A.M.M., Morris, M.E. and Bui, Q.M., 2005. The effects of mode of exercise instruction on compliance with a home exercise program in older adults with osteoarthritis. Physiotherapy, 91(2), pp.79-86.

Shah, B. and Mathur, P., 2010. Surveillance of cardiovascular disease risk factors in India: the need $n$ scope. The Indian journal of medical research, 132(5), p.634.

Shaughnessy, M., Resnick, B.M. and Macko, R.F., 2004. Reliability and validity testing of the short self-efficacy and outcome expectation for exercise scales in stroke survivors. Journal of Stroke and Cerebrovascular Diseases, 13(5), pp.214-219.

Truelsen, T., Begg, S. and Mathers, C., 2006. The global burden of cerebrovascular. In Who Int.

World Health Organization, 2016. World health statistics 2016: monitoring health for the SDGs sustainable development goals. World Health Organization. 